\title{
Chest pain: looking beyond the obvious
}

\author{
Biji Soman, Luke Alexander, Attila Kardos
}

Department of Cardiology, Milton Keynes University Hospital, Milton Keynes, UK

\section{Correspondence to}

Professor Attila Kardos; attila.kardos@cardiov.ox.ac.uk

Accepted 25 January 2021
Check for updates

(c) BMJ Publishing Group Limited 2021. No commercial re-use. See rights and permissions. Published by BMJ.

\footnotetext{
To cite: Soman B, Alexander L, Kardos A. BM Case Rep 2021:14:e241548. doi:10.1136/bcr-2020241548
}

\section{DESCRIPTION}

A septuagenarian woman was admitted with numbness in her left arm and leg and slurring of her speech lasted for a few seconds with full recovery. She also complained of chest pain on mild effort and at rest lasting few minutes with no associated breathlessness or diaphoresis.

She has medical history of type 1 diabetes mellitus, bronchial asthma and right carotid artery stenosis and had intervention to the femoral arteries due to peripheral vascular disease. She has been a non-smoker and independent with good mobility. She lives with her second husband.

She was investigated for angina 4 years ago, and the invasive coronary angiogram (ICA) showed severe triple vessel disease (figure 1, panels $\mathrm{E}$ and $\mathrm{F}$ videos 1 and 2). She was discussed at the Joint Cardiology Cardiothoracic Multidisciplinary meeting and was considered high risk for coronary artery bypass graft surgery due to her extensive comorbidities, and optimised medical treatment was recommended. She has remained stable on medications until this admission.

On examination, she was pain free with no focal neurology. Her blood pressure was $130 / 85 \mathrm{~mm}$ $\mathrm{Hg}$, pulse regular at $65 \mathrm{bpm}$. She had vesicular
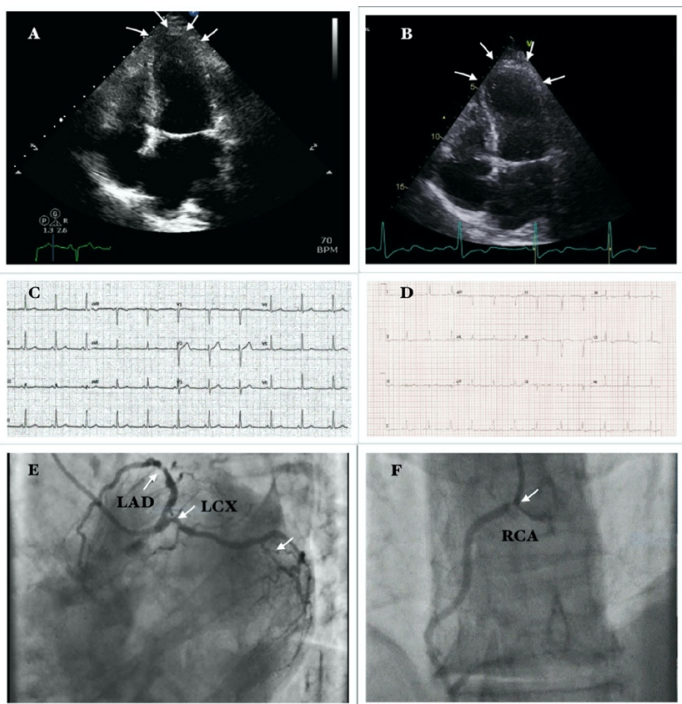

Figure 1 The systolic frames of the apical four-chamber view of the transthoracic echocardiogram (A) and the ECG traces (C) 4 years prior to the current admission and at the time of the admission $(B, D)$ are shown. Note the LV apical ballooning in image $B$. The invasive coronary angiography from 4 years ago shows severe triple vessel disease with critical mid left anterior descending coronary artery (LAD), ostial and distal severe left circumflex coronary artery (LCX) and severe ostial right coronary artery $(R C A)$ disease as indicated by the arrows $(E, F)$.

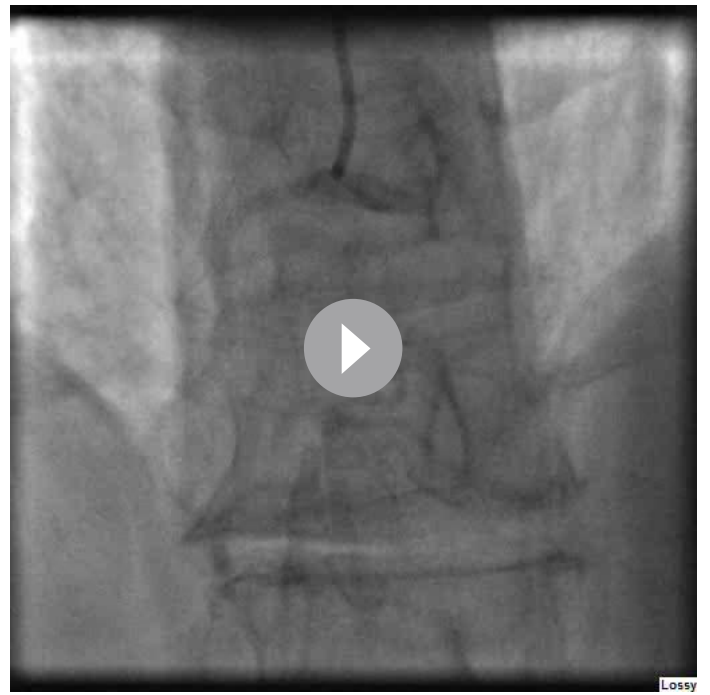

Video 2 Invasive coronary angiograph of the right coronary artery.

breathing sounds and normal heart sounds on auscultation. The other system examinations were normal except week bilateral radial pulses. Laboratory investigations revealed normal inflammatory markers, kidney and liver functions. Her serial high sensitivity cardiac Tropinin I was $111 \mathrm{ng} / \mathrm{L}$ and $4950 \mathrm{ng} / \mathrm{L}$. The CT head did not show acute changes.

Her ECG revealed poor R-wave progression in $\mathrm{V} 1-\mathrm{V} 3$ leads and T wave inversion in I, aVL, V4-V6. The transthoracic echocardiogram (TTE) showed apical dyskinesis with preserved basal wall contraction of the left ventricle (LV) with poor overall LV systolic function. Her ECG and TTE from 4 years ago were normal (figure 1, panels A-D).

With the symptoms of chest pain, new ECG changes, raised cardiac biomarkers and the TTE findings, she was managed as acute coronary syndrome. Over her hospital stay, she remained pain free with no signs of heart failure, and her mobilisation was uneventful.

After in-depth discussion with the patient, it transpired that she had a stressful domestic life that was causing her considerable turmoil and distress. This prompted us to reconsider our diagnosis, and we decided to repeat the TTE before considering a repeat ICA. TTE 5 days later showed the complete recovery of the LV systolic function with no signs of the apical wall motion abnormality (figure 2, videos 3-5). The working hypothesis of stress induced cardiomyopathy was proposed.

She improved symptomatically on medical treatment and was discharged in a haemodynamically stable condition. 


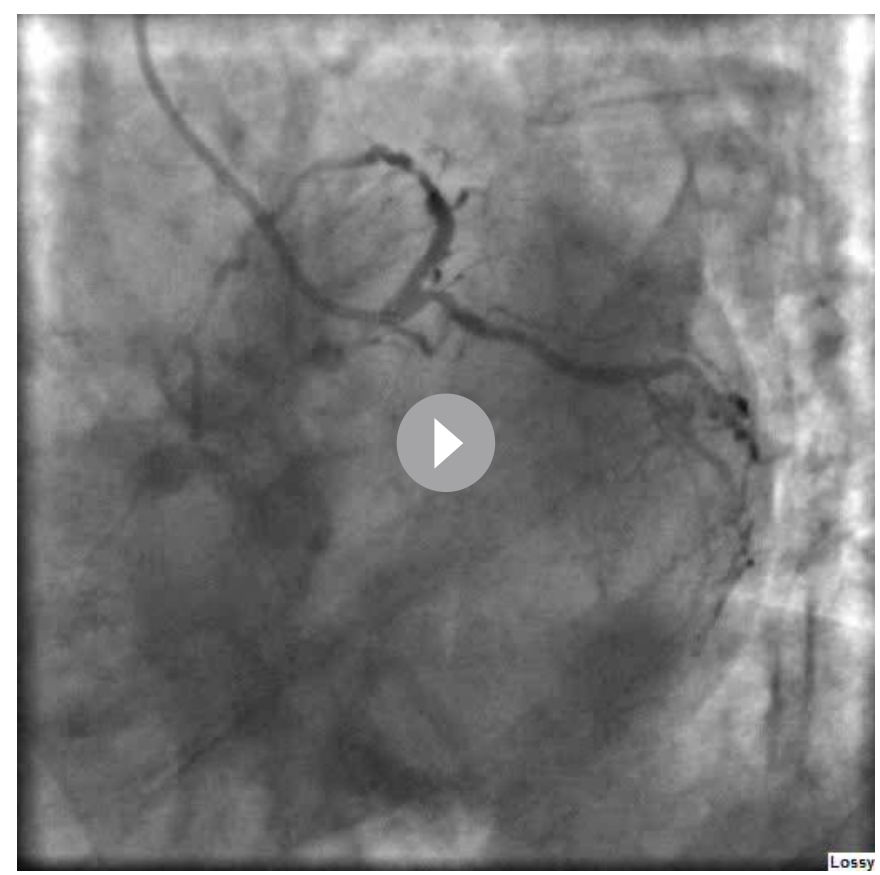

Video 1 Invasive coronary angiograph of the left coronary artery.
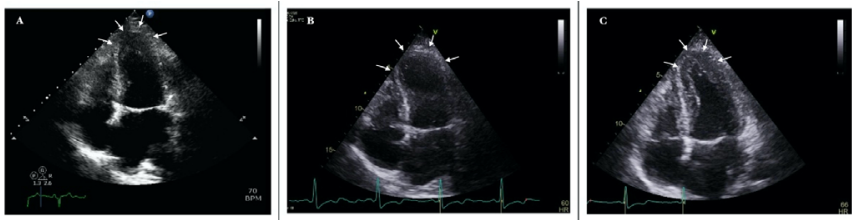

Figure 2 The systolic frames of the four-chamber view of the transthoracic echocardiography 4 years prior to the current admission (A), at the time of the admission (B) and 5 days after her current admission (C) showing normal LV wall motion, apical ballooning and normalised LV motion, respectively, noted by the arrows.

Our case demonstrates, an often-overlooked rare event of emotional stress induced cardiomyopathy with the background of pre-existing coronary artery disease.

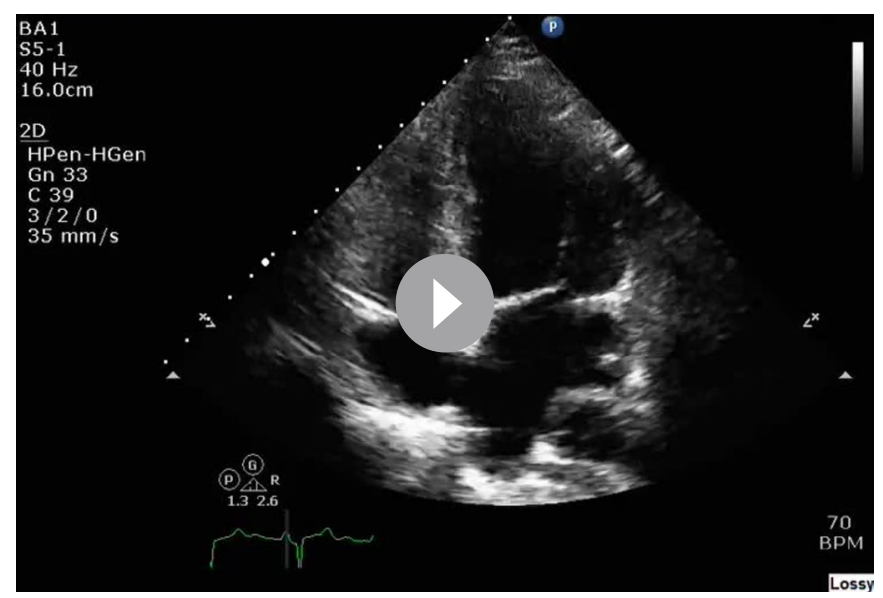

Video 3 Apical 4-chamber view of the transthoracic echocardiogram 4 years prior to the current admission showing no wall motion abnormality.

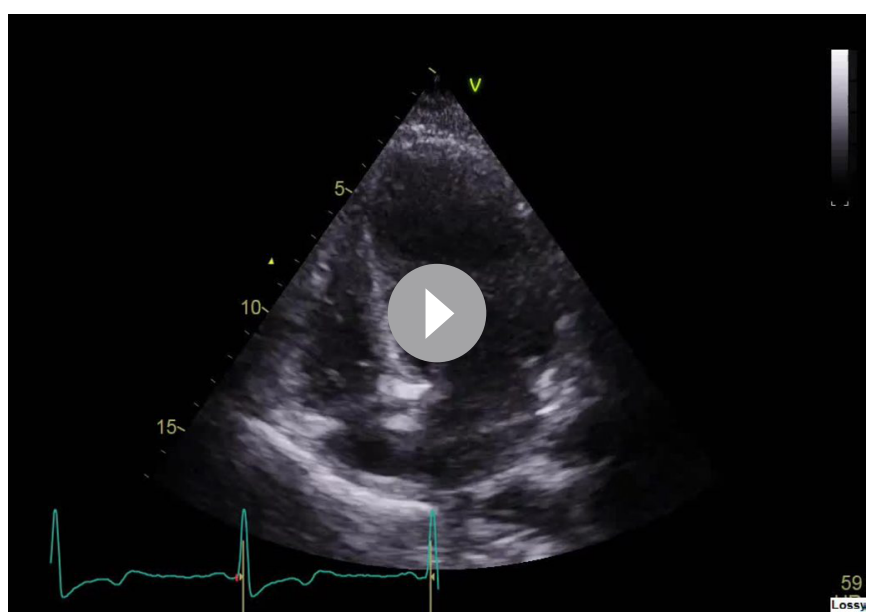

Video 4 At the time of the admission showing apical dyskinesis (ballooning).

Contributors BS and LA prepared the first draft. AK reviewed and edited the final manuscript and was responsible for submission and correspondence. All authors are responsible for the overall content.

Funding The authors have not declared a specific grant for this research from any funding agency in the public, commercial or not-for-profit sectors.

Competing interests None declared.

Patient consent for publication Obtained.

Provenance and peer review Not commissioned; externally peer reviewed.

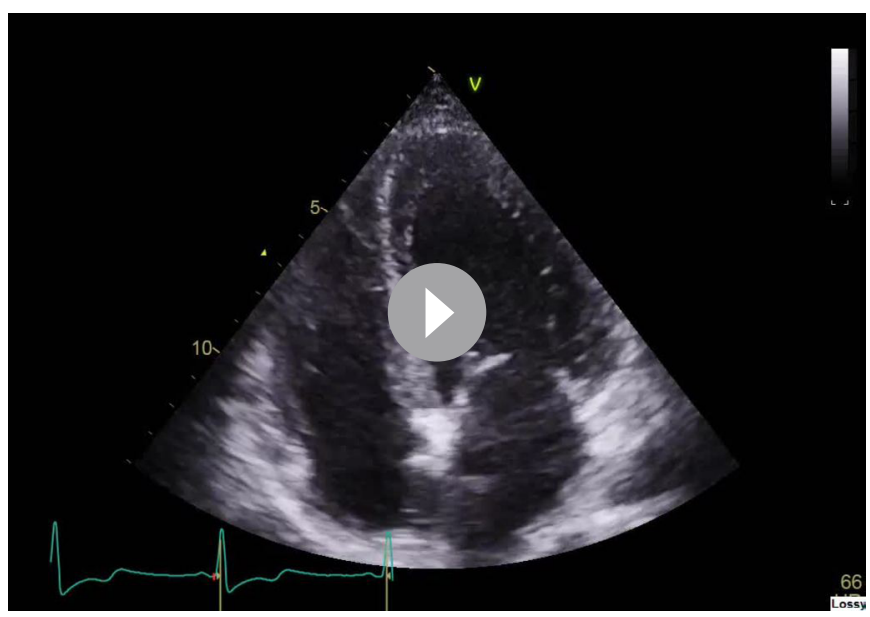

Video 55 days after her current admission showing complete recovery of the apical ballooning.

\section{Learning points}

- The conventional diagnosis of Takotsubo cardiomyopathy (TC) is based on symptoms, raised cardiac biomarkers, abnormal ECG and reversible regional wall motion abnormality with non-obstructive coronary arteries. ${ }^{12}$

- The consensus statement of the European Society of Cardiology in 2018 stated that 'Significant coronary artery disease is not a contradiction in Takotsubo syndrome' as part of the International Takotsubo Diagnostic Criteria. ${ }^{1}$

- With our case, we are raising awareness of the presence of TC even with coexisting triple vessel coronary artery disease. 


\section{REFERENCES}

1 Ghadri J-R, Wittstein IS, Prasad A, et al. International expert consensus document on takotsubo syndrome (Part I): clinical characteristics, diagnostic criteria, and pathophysiology. Eur Heart J 2018;39:2032-46.

2 Ghadri J-R, Wittstein IS, Prasad A, et al. International expert consensus document on takotsubo syndrome (Part II): diagnostic workup, outcome, and management. Eur Heart 2018:39:2047-62.

Copyright 2021 BMJ Publishing Group. All rights reserved. For permission to reuse any of this content visit https://www.bmj.com/company/products-services/rights-and-licensing/permissions/

BMJ Case Report Fellows may re-use this article for personal use and teaching without any further permission.

Become a Fellow of BMJ Case Reports today and you can:

- Submit as many cases as you like

- Enjoy fast sympathetic peer review and rapid publication of accepted articles

- Access all the published articles

Re-use any of the published material for personal use and teaching without further permission

Customer Service

If you have any further queries about your subscription, please contact our customer services team on +44 (0) 2071111105 or via email at support@bmj.com.

Visit casereports.bmj.com for more articles like this and to become a Fellow 